\title{
Período de incubação de Guignardia citricarpa em diferentes estádios fenológicos de frutos de laranjeira 'Valência'
}

\author{
Ronilda L. Aguiar ${ }^{1}$, Eliana M.T. Scaloppi ${ }^{1}$, Antonio de Goes ${ }^{1} \&$ Marcel B. Spósito ${ }^{2}$ \\ ${ }^{1}$ Departamento de Fitossanidade, Universidade Estadual Paulista, Campus de Jaboticabal, 14890-900, Jaboticabal, SP, Brasil; \\ ${ }^{2}$ Departamento de Produção Vegetal, Universidade de São Paulo, ESALQ, 13418-900, Piracicaba, SP, Brazil
}

Autor para correspondência: Ronilda Lana Aguiar, e-mail: ronildaaguiar@yahoo.com.br

\begin{abstract}
RESUMO
A mancha preta dos citros (MPC), causada pelo fungo Guignardia citricarpa, produz lesões em frutos, os quais ficam depreciados para o mercado interno e os restringem para a exportação. $\mathrm{O}$ grande período de suscetibilidade dos frutos cítricos, em adição ao fato de G. citricarpa causar infecções latentes, dificulta o entendimento sobre o período de incubação da doença. O objetivo do trabalho foi determinar o período de incubação da MPC inoculando frutos de laranjeira 'Valência' em diferentes estádios fenológicos. Para a inoculação foram empregadas suspensões de conídios de $G$. citricarpa $\left(10^{3}, 10^{4}, 10^{5}\right.$ e $10^{6}$ conídios $\left.\mathrm{mL}^{-1}\right)$ em diferentes diâmetros dos frutos $(1,5 ; 2,0 ; 2,5 ; 3,0 ; 5,0$ e 7,0 cm). O período de incubação da MPC para os diferentes diâmetros dos frutos inoculados apresentou uma relação polinomial negativa. Em frutos com até $3 \mathrm{~cm}$ de diâmetro o período de incubação médio foi superior a 200 dias, enquanto que em frutos com diâmetros superiores a $5 \mathrm{~cm}$ o período de incubação médio foi inferior a 84 dias. A MPC apresenta período de incubação variável dependente do estádio fenológico em que os frutos são infectados. A concentração de conídios de G. citricarpa, na infecção, não interfere no período de incubação da doença.
\end{abstract}

Palavras-chave: Citrus sinensis, infecção latente, suscetibilidade.

\begin{abstract}
Incubation period of Guignardia citricarpa at the different phenological stages in sweet orange 'Valencia'

Citrus black spot (CBS), caused by Guignardia citricarpa, causes lesions on fruit that depreciate them for the domestic market and restrain them for export. The long susceptibility period in fruit, in addition to the occurrence of latent infection, difficult the understanding of CBS incubation period. The aim of this study was to determine the incubation period of CBS by inoculating fruits of 'Valencia' orange at different phenological stages. Conidia suspensions of $G$. citricarpa at different concentrations $\left(10^{3}, 10^{4}, 10^{5}\right.$ and $\left.10^{6} \mathrm{conidia}^{\mathrm{mL}} \mathrm{L}^{-1}\right)$ were inoculated in fruit of different diameters $(1.5,2.0,2.5,3.0,5.0$ and $7.0 \mathrm{~cm})$. The relationship of CBS incubation period with fruit diameter was polynomial negative. The average incubation period for $3 \mathrm{~cm}$ fruit was over 200 days, while fruit which were greater than $5 \mathrm{~cm}$ in diameter had an average incubation period of less than 100 days. CBS incubation period is therefore variable and depends on the phenological stage in which the fruit have been infected. The concentration of G. citricarpa conidia did not interfere with the incubation period of the disease.
\end{abstract}

Key words: Citrus sinensis, latent infection, susceptibility.

A mancha preta dos citros (MPC), causada pelo fungo Guignardia citricarpa, afeta todas as variedades comerciais de laranjeiras doces (Aguilar-Vildoso et al., 2002). A doença produz lesões nos frutos, os quais tornamse depreciados para o mercado interno de fruta fresca e os restringem para a exportação. No campo, em condições de alta intensidade da MPC, pode ocorrer queda prematura de frutos reduzindo a produtividade do pomar (Feichtenberger et al., 2005).

As variedades comerciais de laranjeiras doces possuem o mesmo grau de suscetibilidade à MPC (Spósito et al., 2004), entretanto a expressão dos sintomas ocorre em maior intensidade em variedades tardias, como a 'Valência', 'Natal' e 'Folha Murcha' (Feichtenberger et al., 2005). A expressão dos sintomas está relacionada às condições ambientais, como altas temperaturas e intensidade de radiação solar (Kotzé, 1963; Feichtenberger, 1996).
Após a infecção em frutos, G. citricarpa permanece latente formando uma massa de micélio sob a cutícula (Brodrick \& Rabie, 1970). Os sintomas da MPC se expressam com a maturação dos frutos (Calavan, 1960). Entretanto, as infecções que deram origem aos sintomas podem ter ocorrido em qualquer período após a queda das pétalas (Kotzé, 1981; Baldassari, et al., 2006). O período crítico para essas infecções inicia-se com a queda de pétalas e estende-se até 4 a 5 meses (Kotzé, 1996). Infecções tardias também podem ocorrer e levar à queda prematura dos frutos (Baldassari, et al., 2006; Almeida, 2009; Scallopi, 2010).

Devido ao longo período de suscetibilidade dos frutos, em conjunto com a ocorrência de infecção latente, não se sabe se o período de incubação da MPC é constante e recorrente de novas infecções sequenciais, ou variável, determinado por fatores relacionados à fenologia do fruto. 
O conhecimento do período de incubação de $G$. citricarpa tem como importância a definição de uma melhor estratégia de controle da doença visando a redução de inóculo da área e das perdas causadas pela queda prematura dos frutos (Bergamin Filho \& Amorim, 2002; Scallopi, 2010).

Com o intuito de ampliar o conhecimento do patossistema citros - G. citricarpa e aprimorar o controle da doença, o presente trabalho teve como objetivo determinar o período de incubação da MPC em frutos de laranjeira 'Valência'.

Utilizou-se no experimento um isolado monospórico de G. citricarpa reconhecidamente patogênico. A suspensão de conídios foi obtida a partir de culturas do isolado presentes em placas de Petri contendo meio batata-dextrose-ágar (BDA), previamente incubadas a $24^{\circ} \mathrm{C} \pm 1{ }^{\circ} \mathrm{C}$ durante 30 dias. Após esse período, foi depositada sobre as colônias 10 $\mathrm{mL}$ de água destilada esterilizada acrescida de uma gota de Tween 20, seguido de raspagem superficial com pincel de cerdas macias para a liberação dos conídios. Após filtragem em camada dupla de gaze, a suspensão obtida teve sua concentração calibrada para quatro concentrações: $10^{3}, 10^{4}$, $10^{5}$ e $10^{6}$ conídios $\mathrm{mL}^{-1}$, com o uso de hemocitômetro.

As inoculações foram realizadas em frutos de plantas de laranjeira doce 'Valência' (Citrus sinensis Osbeck), enxertadas em limoeiro 'Cravo' (Citrus limonia Osbeck), com três anos de idade, mantidas em vasos em casa-devegetação. As suspensões de conídios foram inoculadas com o uso de atomizador manual até o ponto de escorrimento, para os diferentes diâmetros de frutos: 1,$5 ; 2,0 ; 2,5 ; 3,0 ; 5,0$ e 7,0 cm. Nas testemunhas, para cada diâmetro de frutos, aplicou-se água destilada. Em cada combinação diâmetro de fruto por concentração de conídios foram inoculados oito frutos. Após a inoculação as plantas foram mantidas por 24 horas sob nebulização a $100 \%$ de umidade relativa. As avaliações foram feitas diariamente, até o aparecimento do primeiro sintoma. Após a visualização dos sintomas as avaliações foram realizadas quinzenalmente durante 282 dias. O experimento foi conduzido inteiramente ao acaso, considerando-se cada fruto como uma repetição. Os dados de período de incubação em relação ao diâmetro do fruto inoculado, para cada concentração de inóculo testada, foram submetidos à análise de regressão, com o software Statistica - Stat Soft, versão 6.0.
Para as diferentes concentrações de conídios de $G$. citricarpa $\left(10^{3}, 10^{4}, 10^{5}\right.$ e $10^{6}$ conídios $\left.\mathrm{mL}^{-1}\right)$ utilizadas nas inoculações dos frutos, não foram observadas diferenças quanto ao período de incubação da MPC (Tabela 1). Portanto, a concentração do patógeno está relacionada ao tipo de sintoma da MPC expresso (Almeida, 2009), e não ao período de incubação da doença.

Quanto às inoculações feitas em frutos com diferentes diâmetros, observou-se uma relação polinomial negativa entre o período de incubação e o diâmetro dos frutos inoculados (Figura 1). O período de incubação observado, portanto, foi variável. Frutos com até $3 \mathrm{~cm}$ de diâmetro expressaram sintomas em média após 230 dias, enquanto que em frutos com diâmetros iguais ou superiores a 5,0 cm, o período para expressão de sintomas foi, em média, inferior a 84 dias (Tabela 2). No campo, os primeiros sintomas da MPC são observados por volta de seis meses após a queda de pétalas (Alcoba, 2000). De acordo com os dados obtidos no experimento, a observação feita no campo está provavelmente relacionada às infecções em frutos logo após a queda de pétalas. A variação observada no período de incubação da MPC também é observada em outros patossistemas, como a podridão parda do pessegueiro (Prunus persicae) causada por Monilinia fructicola e em diversas antracnoses de fruteiras tropicais causadas por Colletotrichum gloeosporioides (Verhoeff, 1974; Prusky \& Plumbley, 1992).

O período de incubação variável pode estar relacionado à resistência de frutos imaturos à colonização pelo patógeno, baseado em mecanismos como compostos tóxicos presentes nos frutos imaturos, presença de substâncias complexas inadequadas para a nutrição do patógeno, quantidade inadequada de enzimas produzidas pelo patógeno para degradar as substâncias pécticas da parede celular do fruto, ou produção de fitoalexinas nos frutos pós-infecção (Jeffries et al., 1990). Segundo Benato (2002), o processo de amadurecimento e senescência dos frutos geralmente reduz a intensidade das respostas de resistência.

Essa variação no período de incubação da MPC implica direta e indiretamente nas medidas de controle a serem adotadas. Para Feichtenberger et al. (1997), pulverizações com fungicidas visando a proteção dos frutos

TABELA 1 - Coeficiente angular (a), interseção (b) e coeficiente de determinação $\left(\mathrm{R}^{2}\right)$ das regressões lineares entre período de incubação e diâmetro dos frutos, para diferentes concentrações de inóculo de Guignardia citricarpa

\begin{tabular}{lcccc}
\hline \hline Concentrações & \multicolumn{2}{c}{ Parâmetros das equações } \\
$\mathbf{a}^{\mathbf{z}}$ & $\mathbf{b}^{\mathbf{z}}$ & $\mathbf{F}^{\mathbf{w}}$ & $\mathbf{R}^{\mathbf{2}}$ \\
\hline $10^{3}$ & $-34,62 \mathrm{a}$ & $315,23 \mathrm{a}$ & $30,88^{* *}$ & 0,70 \\
$10^{4}$ & $-41,66 \mathrm{a}$ & $317,24 \mathrm{a}$ & $93,88^{* *}$ & 0,89 \\
$10^{5}$ & $-38,79 \mathrm{a}$ & $295,94 \mathrm{a}$ & $71,35^{* *}$ & 0,86 \\
$10^{6}$ & $-34,10 \mathrm{a}$ & $254,5 \mathrm{a}$ & $26,50^{* *}$ & 0,75 \\
\hline
\end{tabular}

\footnotetext{
${ }^{\mathrm{z}}$ Médias seguidas pela mesma letra nas colunas não diferem estatisticamente entre si pelo teste de Tukey $(P<0,05)$.

w ** $1 \%$ de probabilidade estimada na análise de regressão linear.
} 


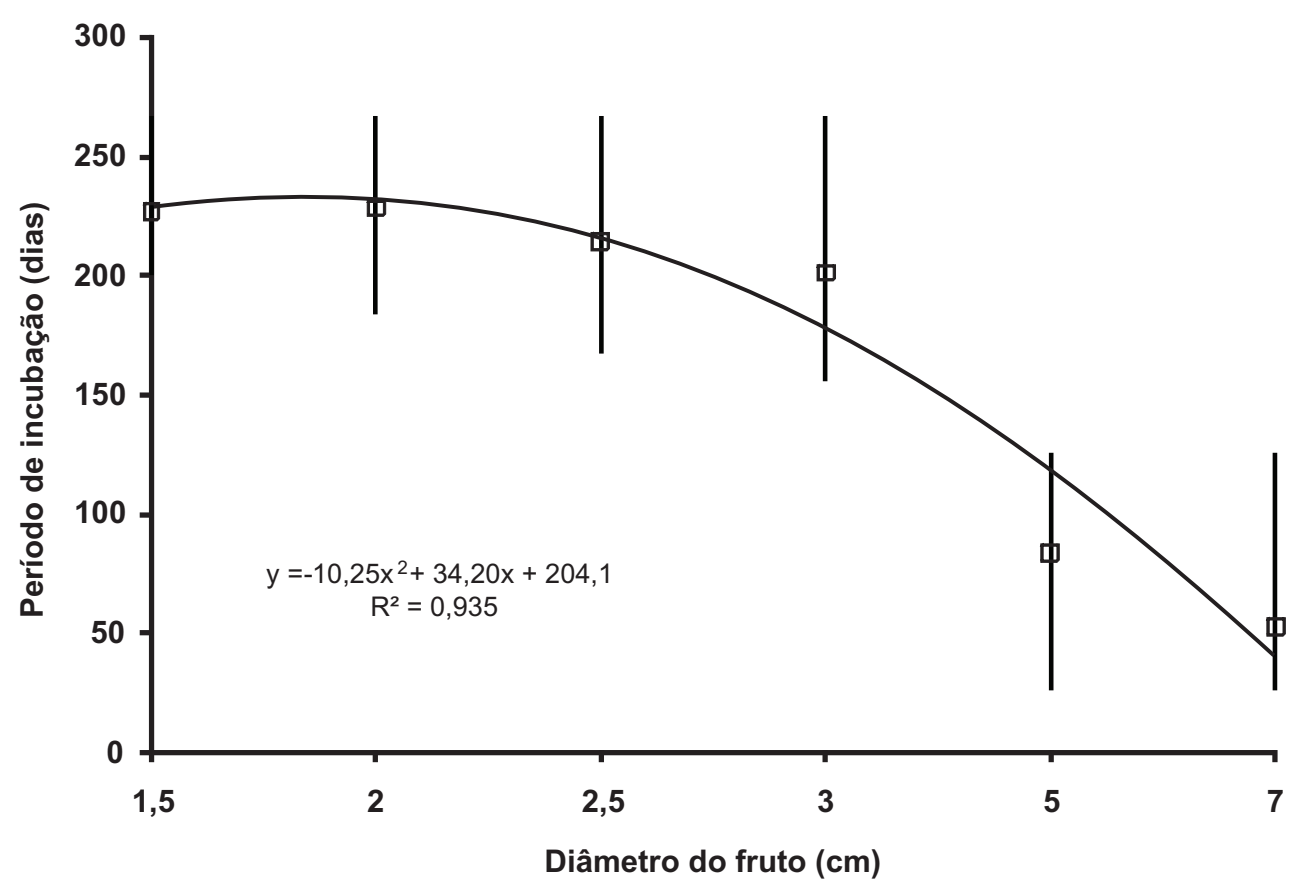

FIGURA 1 - Período de incubação médio da mancha preta dos citros, causada por Guignardia citricarpa, em relação ao diâmetro de frutos de laranjeira 'Valência' inoculados com suspensão de conídios do patógeno. Plantas mantidas em casa-de-vegetação.
TABELA 2 - Período de incubação médio da mancha preta dos citros, causada por Guignardia citricarpa, em frutos de laranja 'Valência' com diferentes diâmetros, inoculados com suspensão de conídios do patógeno

\begin{tabular}{cc}
\hline \hline Diâmetro do fruto (cm) & Período de incubação (dias) \\
\hline 1,5 & $227,3 \mathrm{a}$ \\
2,0 & $228,7 \mathrm{a}$ \\
2,5 & $214,8 \mathrm{~b}$ \\
3,0 & $201,5 \mathrm{c}$ \\
5,0 & $84,5 \mathrm{~d}$ \\
7,0 & $53,6 \mathrm{e}$ \\
\hline
\end{tabular}

$\overline{\text { Médias seguidas pela mesma letra não diferem estatisticamente entre }}$ si pelo teste de Tukey $(P<0,05)$.

durante o período de suscetibilidade devem ocorrer pelo menos 4-5 meses após a queda das pétalas. Entretanto, a expressão de sintomas próximos ao pedúnculo dos frutos pode levar a sua queda prematura, reduzindo a produção do pomar (Scallopi, 2010). Os resultados do experimento mostraram que os sintomas tardios que podem levar à queda prematura dos frutos cítricos são originários de infecções tardias. Frutos com 5 a $7 \mathrm{~cm}$ de diâmetros apresentaram um período de incubação inferior a 84 dias. Ou seja, infecções próximas ao pedúnculo irão expressar sintomas próximos ao pedúnculo, levando à queda precoce dos frutos. Quando as infecções ocorreram em frutos ainda em desenvolvimento (2,0, 2,5 e $3 \mathrm{~cm}$ de diâmetro), o período de incubação é longo e mesmo que a infecção ocorra próxima ao pedúnculo a expressão dos sintomas ocorrerá distante desse local, uma vez que o crescimento do fruto cítrico se dá a partir da região peduncular em direção à região estilar (Spósito, 2010). Portanto, dependendo da finalidade da produção dos frutos cítricos de áreas com a MPC (indústria, mercado interno ou exportação) diferentes estratégias de controle deverão ser tomadas, levando-se em consideração o período de incubação variável e, portanto, os diferentes estádios fenológicos em que ocorre a infecção dos frutos cítricos por G. citricarpa.

\section{REFERÊNCIAS BIBLIOGRÁFICAS}

Aguilar-Vildoso CI, Ribeiro JGB, Feichtenberger E, Goes A, Spósito MB (2002). Manual Técnico de Procedimentos da Mancha Preta dos Citros. Brasília. MAPA/SDA/DDIV.

Alcoba NJ, Vigiani AR, Bejarano NV, Alvarez SE, Serrano MA, Bonillo MC (2000) Mancha negra de los cítricos: Epidemiologia y control. San Salvador de Jujuy, Argentina. Ediciones Universidad Nacional de Jujuy.

Almeida TF (2009) Mancha preta dos citros: Expressão dos sintomas em frutos pela inoculação com conídios e controle do agente causal (Guignardia citricarpa). Tese de Doutorado. Faculdade de Ciências Agrárias e Veterinárias, Universidade Estadual Paulista. Jaboticabal SP.

Baldassari RB, Reis RF, Goes A (2006) Susceptibility of fruits of the 'Valência' and 'Natal' sweet orange varieties to Guignardia citricarpa and the influence of the coexistence of healthy and symptomatic fruits. Fitopatologia Brasileira 31:337-341.

Benato EA (2002) Principais doenças em frutas pós-colheita e métodos alternativos de controle com potencial de indução de 
resistência. In: Anais, Simpósio de controle de doenças de plantas: Patologia pós-colheita de frutos e hortaliças. Lavras MG. pp. 4046.

Bergamin Filho A, Amorim L (2002) Doenças com período de incubação variável em função da fenologia do hospedeiro. Fitopatologia Brasileira 27:561-565.

Bodrick HT, Rabie CJ (1970) Light and temperature effects on symptom development and sporulation of Guignardia citricarpa Kielt, on Citrus sinensis (Linn) Osbeck. Phytophylactica 2:157164.

Calavan EC (1960) Black spot of citrus. California Citrograph 46:21-24.

Feichtenberger E (1996) Mancha-preta dos citros no Estado de SãoPaulo. Laranja 17:93-108.

Feichtenberger E, Müller GW, Guirado N (1997) Doenças do citros. In: Kimati H, Amorim L, Bergamim Filho A, Camargo LEA, Rezende JAM (Eds.). Manual de fitopatologia: Doenças das plantas cultivadas. $3^{\mathrm{a}}$ ed. São Paulo SP. Agronômica Ceres. pp. 261-296.

Feichtenberger E, Bassanezi RB, Spósito MB, Belasque J (2005) Doenças dos citros (Citrus spp.). In: Kimati H, Amorim L, Rezende JAM, Bergamin Filho A, Camargo LEA (Eds.). Manual de fitopatologia: Doenças das plantas cultivadas. $4^{\mathrm{a}}$ ed. São Paulo SP. Agronômica Ceres. pp. 475-476.

Jeffries P, Dodd JC, Jeger MJ, Pumbley RA (1990) The biology and control for Colletotrichum species on tropical fruit crops.
Plant Pathology 39:343-366.

Kotzé JM (1963) Studies on the black spot disease of citrus caused by Guignardia citricarpa Kiely with particular reference to its epiphytology and control at Lebata. PhD Thesis. University of Pretoria. Pretoria, South Africa.

Kotzé JM (1981) Epidemiology and control of citrus black spot in South Africa. Plant Disease 65:945-950.

Kotzé JM (1996) History and epidemiology of citrus black spot in South Africa. Proceedings of the International Society of Citriculture 2:1296-1299.

Prusky D, Plumbley RA (1992) Quiescent infections of Colletotrichum in tropical and subtropical fruits. In: Bailey JA, Jeger M (Eds.) Colletotrichum: Biology, Pathology and Control. Wallingford UK. CAB International. pp. 289-307.

Scaloppi EMT (2010) Mancha preta dos citros: Técnicas de manejo e queda precoce de frutos. Tese de Doutorado. Faculdade de Ciências Agrárias e Veterinárias, Universidade Estadual Paulista. Jaboticabal SP.

Spósito MB, Bassanezi RB, Amorim L (2004) Resistência à mancha preta dos citros avaliada por curvas de progresso da doença. Fitopatologia Brasileira 29:532-537.

Spósito MB (2010) Atualização no controle da pinta preta dos citros. Citricultura Atual 77:8-10.

Verhoeff K (1974) Latent infections by fungi. Annual Review of Phytopathology 12:99-110.

TPP 250 - Recebido 13 Fevereiro 2011 - Aceito 18 Março 2012 Editor de Seção: F. Murilo Zerbini 